\title{
Personality Styles, Psychological Adjustment and Gender Differences in Parents of Children with Congenital Disabilities
}

\author{
Rosa M. Limiñana-Gras',2, María del Pilar Sánchez-López ${ }^{3,4}$, María Teresa Calvo-Llena², \\ Francisco Javier Corbalán ${ }^{2}$ \\ ${ }^{1}$ Research Group Personality and Health: A Intercultural and Gender Perspective, Murcia, Spain \\ ${ }^{2}$ Universidad de Murcia, Murcia, Spain \\ ${ }^{3}$ Universidad Complutense de Madrid, Madrid, Spain \\ ${ }^{4}$ Red Hygeia (Health \& Gender International Alliance), Madrid, Spain \\ Email: liminana@um.es
}

Received 23 July 2015; accepted 10 November 2015; published 13 November 2015

Copyright (C) 2015 by authors and Scientific Research Publishing Inc.

This work is licensed under the Creative Commons Attribution International License (CC BY).

http://creativecommons.org/licenses/by/4.0/

(c) (7) Open Access

\section{Abstract}

The present study analyzes the psychological adaptation of parents with children having congenital disabilities. The study included 83 men and 96 women, who were parents of children with severe spina bifida, cerebral palsy, cleft lip and cleft palate. The Millon Index of Personality Styles was used to identify the most distinctive personality styles of parents caring for a child with a chronic disability and parental psychological adjustment. We also investigated if personality profiles differ by gender, and educational and socioeconomic level. The personality styles identified may serve as indicators of the way parents adapt to the child with a congenital disability. The results also suggest that a child's disability has a differential impact on men and women. Gender issues are evaluated, as well as any repercussions these may have on women.

\section{Keywords}

Personality Styles, Congenital Disability, Parental Psychological Adjustment, Gender Differences

\section{Introduction}

The physical and psychological health of parents with children suffering from congenital malformations or diseases has become a topic of increasing interest. A review of the literature shows that most studies focus on the risks and vulnerabilities most frequently observed in this group [1]-[3], and particularly among mothers since 
they are the main caregivers [4] [5]. Most studies describe the presence of anxiety, stress, economic problems and family conflicts [6]-[10].

Practically every study confirms that the birth of a child with a chronic disease or disability involves painful long-term experiences and that parents are at increased risk of developing psychosocial problems [11]-[15].

Other studies have investigated the process of adaptation to chronic stress induced by caring for a child with a disability [16]-[19]. They report that the management or coping strategies used, continuously change over time, which increases the complexity of measuring such adaptation processes.

In the context of caring for disabled children, personality variables also have been identified as powerful factors that could explain individual differences in how parents face chronic stress. Most of these studies have identified personality traits using factorial models [5] [20]-[22].

Less frequent in this context are studies in which personality has been regarded as a mediating variable or as a predictor of coping [23]-[25].

The present study used Millon's Personality Model [26]-[28] to investigate and analyze the process of adaptation to chronic stress. This model allows us to use relatively stable variables, while still showing how parents cope with the situation and adapt to the child's disability. In the Millon Index of Personality Styles (MIPS), the concept of style is understood from an evolutionary perspective, whereby personality is organized into stable sets of adaptive functioning. This instrument has some advantages over other personality questionnaires because it has a dynamic perspective of human behavior, which enables the evaluation of styles rather than fixed or static personality traits. It focuses on the normal personality and includes three main areas: Motivating Styles, with a theoretical basis that derives from ecological and evolutionary theories; Thinking Styles, that are based on evolutionary perspectives, and the contributions of Jung and Myers; and Behaving Styles, are influenced by Sullivan, Leary, and the Five Factors Model.

Thus, a personality style is regarded as a set of traits derived from biological tendencies and experiential learning that characterizes a relatively stable way of behaving. The personality styles have proved more susceptible to environmental changes than traditional traits (more stable and definitive), and sufficiently sensitive to evaluate the adaptive functioning with more consistency and stability than other variables more situationally determined [26]. Models that have mainly focused on health have identified traits such as optimism, self-esteem, parental competence, resilience, the rewards and satisfaction of caring for the child, and problem-resolution skills as personality resources that have a positive effect on the stress management involved in caring for a child with disabilities [13] [29]-[31]. However, these are isolated variables that do not include all the personality dimensions that modulate the behavior of the individual.

In contrast to factorial models or multi-trait concepts, the Millon model involves a multidimensional approach to normal personality, and is based on integrating bio-psychosocial, evolutionary, and ecological viewpoints. Millon's concept of normal personality and his comprehensive approach to the person as a whole means that the MIPS (MIPS-Millon) [27] [28] includes a set of variables that are sufficiently broad to cover the range of behaviors found in parental adaptation to disability. On the other hand, the variables are simple enough to provide clear and accurate information that may contribute to future research and intervention. Another relevant point is that they provide a non-dysfunctional personality model that helps to identify parents' psychological resources.

The MIPS also includes a Clinical Index [27] that measures the degree to which a person adapts to your environment, compared to their reference group. Other studies incorporated the Clinical Index as an overall measure or indicator of psychological adjustment [24] [32], showing their relationship to psychological health in the health context [25] [33], and confirming the utility of this measure as an indicator of more adaptation to the environment and therefore as indicator of psychological adjustment.

Within the framework of this model, we studied the medium- and long-term impact on parental psychological organization and functioning, of having a child with a disability. The study aims were as follows: To identify stable adaptive functioning styles in these mothers and fathers, and their differences with normative population; to evaluate parental psychological adjustment and adaptability by using the Clinical Index; and to analyze the modulating effect of gender, educational and the socioeconomic level, on parent's personality styles and psychological adjustment.

The study included parents of children with severe spina bifida or Myelomeningocele (MM), cerebral palsy, and cleft lip and cleft palate. MM is the most common and severe form of spina bifida and the most common of the neural tube defects, a congenital medical condition in which the neural tube fails to close completely during 
early gestation, and is associated with sensory, motor and cognitive impairments [34]. Cerebral palsy is a group of permanent neurological disorders of the development of movement and posture that are caused by to no progressive disturbances that occurred in the development in fetal or infant brain. The motor disorders of cerebral palsy are often accompanied by disturbances of sensation, perception, cognition, communication, and behavior, epilepsy, and secondary musculoskeletal problems [35]. Cleft lip or cleft palate is an embryonic syndrome which accounts for $65 \%$ of all the congenital malformations of the head and the neck [36]. Cleft lip and cleft palate in newborns have implications for feeding, the child's psychosocial adjustment and growth is affected by factors including reactions to surgeries, and parents needed support beyond information about feeding after birth.

Taking into account the literature and the study aims, we formed three hypotheses: firstly, parents of children with disabilities will present personality styles significantly different from the normative population revealing a differential adaptive functioning; secondly, since mothers normally carry the main workload of caring for the child, mothers in this group will show a psychological adjustment (Clinical Index) significantly lower than women in the normative population, and also lower than the parents in this group; thirdly, the gender, the educational and the socioeconomic level of the parents, will moderate the differences observed in personality styles and psychological adjustment.

\section{Method}

\subsection{Participants}

The study included 83 men (46.4\%) and 96 women (53.6\%), both of Spanish nationality, who were parents of children with severe spina bifida (MM), cerebral palsy, and cleft lip and cleft palate. Of these, $87.2 \%$ (78 couples) belong to the same family, that is, they are fathers and mothers of the same child; and $12.8 \%$ not belonging to the same family, that is, only one parent has participated (5 fathers and 18 mothers). The age of the parents ranged from 22 years to 72 years $\mathrm{M}=39.81$, $\mathrm{SD}=8.27$ ). There were no statistically significant differences between the age of fathers and mothers [t $(177)=1.43 ; p<0.15]$.

In total, $88.8 \%$ of the participants were married, $2.8 \%$ were separated or divorced, $1.1 \%$ were widows or widowers, and approximately $7.3 \%$ were single. The educational level was evenly distributed in the sample (35.2\% had completed primary education, $34.6 \%$ secondary education, and $30.2 \%$ higher education). A significantly greater percentage of participants were working at the time of the study (74.9\%); $18.2 \%$ were housewives, $3.4 \%$ were unemployed, and the remaining $2.8 \%$ were retired. Around $57 \%$ of participants had a low to medium socioeconomic level, whereas $43 \%$ had a medium to high level.

The mean age of the children was 8.04 (SD = 7.88), 12.3\% are one year old or younger, $30.2 \%$ (1 thru 4) 36.3\% (4 thru 12) and $21.2 \%$ are o are twelve year old or greater (to 28 ) ranging from 4 months to 28 years. Of these, 67 (66.3\%) were diagnosed with severe spina bifida (myelomeningocele), 20 (19.8\%) with cleft lip and cleft palate, and 14 (13.9\%) with cerebral palsy. As an indicator of the severity of the child's disability, functional limitation was calculated and expressed in percentages using Spanish instruments that followed the WHO international guidelines [37] [38]. The mean percentage in our study group was $52.50(\mathrm{SD}=21.05)$ ranging from $20 \%$ to $91 \%$. The mean percentage in group diagnosed with myelomeningocele was 53.91 (SD = 20.65), in group diagnosed with cleft palate 33.84 (SD = 19.42), and in group diagnosed with cerebral palsy 58.31 (SD = 19.42).

\subsection{Instruments}

Questionnaire on socio-demographic data and the child's disease:

The parents completed a socio-demographic and clinical questionnaire, designed for this study. The first questionnaire collected basic demographic data of participants as the age, number of children, sex, marital status, place of residence, educational level, socioeconomic status and employment status or occupation. Socioeconomic status was measured as a combination of economic status, education and employment status or occupation.

The secondly collected child's clinical data: the child's diagnosis and severity of the disability; number of surgeries and hospitalizations; physical and neurological complications such as phonatory alterations, alterations of deglutition, paralysis, poor renal function, Arnold Chiari II malformation, scoliosis, back pain, and worsening bowel and/or bladder function, etc.; as well other difficulties, e.g. executive functions, selective attention or focused attention. 
Millon Index of Personality Styles (MIPS):

This instrument adapted and validated for use in the Spanish population by Sánchez-López, Díaz, and Aparicio [39], assesses the normal personality. The MIPS [27] [28] provides a measure of personality styles organized according to tree key dimensions: Motivating styles, Thinking styles, and Behaving styles. It includes 24 scales, plus three validity control indexes. The scales are organized in bipolarities, 12 pairs of scales that are opposites from a theoretical viewpoint, although not in the psychometric sense, since each scale was designed in such a way that it could be measured independently from its opposite. First, three pairs of scales in the Motivating styles dimension: Pleasure/Enhancing and Pain/Avoiding, Actively Modifying and Passively Accommodating, Self-Indulging and Other Nurturing. Secondly, four pairs of scales in the Thinking Styles dimension: Externally Focused and Internally Focused, Realistic/Sensing and Imaginative/Intuiting, Thought-Guided and FeelingGuided, Conservation-Seeking and Innovation-Seeking. And finally, five pairs of scales in the Behaving styles dimension: Asocial/withdrawing and Gregarious/outgoing, Anxious/hesitating and Confident/asserting, Unconventional/dissenting and Dutiful/conforming, Submissive/yielding and Dominant/controlling, Dissatisfied/ complaining and Cooperative/agreeing.

The MIPS also incorporates an adjustment index (Clinical Index-Millon) [27] to measure the degree to which a person adapts to your environment, compared to their reference group. This index is obtained by weighting the scores on the scales "Pleasure/Enhancing and Pain/Avoiding" (Motivating styles) and the five pairs of scales in the Behaving styles dimension. This index was developed from theoretical and empirical foundations. The construct validity has been proven through its relationship with measures of psychological well-being or mental health [40] [24] [33] [39]. The internal consistency of the scale in the Spanish population is satisfactory (0.72), and the mean for all scales was 0.73 in the study sample. Details on the psychometric properties of the MIPS (i.e. internal consistency, temporal stability, and convergent and discriminant validity) in the Spanish population [39] and the American population [27] [28] have been previously published.

\subsection{Procedure}

The selection of participants was performed with the collaboration of Spanish parent associations of children with spina bifida, cerebral palsy, cleft lip and palate. The selection criterion used to recruit participants was having a child with a chronic physical illness.

The tests were administered by the clinical psychologist leading the study. The study protocol was approved by the Bioethics Committee of the University of Murcia and all participants gave their informed consent after the purpose of the research was explained and participation was voluntary. The anonymity of the data was also ensured. Parent associations provided space in their own centres, sent out the invitations by post, and scheduled the interviews and test administration sessions with both parents, who filled in the tests independently.

\subsection{Data Analysis}

Data were analyzed using the statistical software package SPSS 19.0 for Windows. Pearson's correlation coefficient was used to analyze the linear relationship between the psychological and demographic variables. Differences between the sample mean and the normative mean were analyzed using the Student t-test, (95\% confidence interval) and the mean scores for the Spanish population were used as the test value [27] (Spanish adaptation). The Spanish normative sample was made up of 1184 adults, consisting of 643 women (54.3\%) and 541 men (45.7\%), with a mean age of 37.60 years. The Spanish adaptation of the Millon test provides basic statistics for the total adult normative population used in the study, and for women and men; thus, the study sample can be compared to the normative group according to gender. The effect sizes were calculated using Cohen's $\mathrm{d}$ based on sample size (Hedges Adjustment) to control for size differences in the 2 study groups.

A Multiple Analysis of Covariance (MANOVA) was performed to investigate the moderating effect of gender and sociodemographic variables on the differences in personality styles and psychological adjustment. We have followed a process of statistical modeling in which as a first step we tested the significance of the more complete model. The independent variables or factors to control for the differences between groups were gender, educational level and socioeconomic level. The covariates were age (age of parents and child) and the severity of the disability. However we have found no relationship between these covariates and dependent variables, so we have chosen not to include it. Before performing the MANOVA, normality and homogeneity of variance were verified (Box Test, Levene's test) as well as the correlation between the dependent variables (Bartlett's test of 
sphericity). The indexes for the effect size were also calculated using Partial Eta Squared $\left(\eta^{2}\right)$, which indicates the proportion of variance explained by each variation source [41].

\section{Results}

Analysis of the MIPS indexes indicates that, in general, the parents did not attempt to give either a very positive image ( $M$ score IP $=3.3$; $S D=2.1$ ) or a very negative image of themselves $(M$ score $I N=2.7$; $S D=2.2)$. Furthermore, the mean value obtained for Consistency ( $M$ score $C=3.5$; $S D=1.1)$, and the analysis of minimum values (range $=2-5$ ), confirmed that the parents were consistent in their responses. There no statistically significant correlations were between the personality scales and the age of parents and children.

Table 1 shows the means, standard deviations, and the results of the Student t-test and Cohen's $d$ on the MIPS scales and the Clinical Index for men and women (Hypothesis 1 and 2). The results show statistically significant differences in the personality styles of the men and women of our sample compared to the normative group.

Table 1. Means, standards deviations, Student t and effect sizes (d) in men and women on the MIPS scales.

\begin{tabular}{|c|c|c|c|c|c|c|c|c|}
\hline \multirow{3}{*}{ MIPS scales } & \multicolumn{8}{|c|}{ MIPS Personality Styles $(\mathrm{N}=179)$} \\
\hline & \multicolumn{4}{|c|}{ Men (n = 83) } & \multicolumn{4}{|c|}{ Women $(n=96)$} \\
\hline & $M(S D)$ & $t(82)$ & $p$ & $d$ & $M(S D)$ & $t(95)$ & $p$ & $d$ \\
\hline \multicolumn{9}{|l|}{ Motivating Styles } \\
\hline 1A. Pleasure-Enhancing & $25.95(6.33)$ & 3.27 & 0.002 & 0.33 (mod.) & $22.65(7.32)$ & -0.57 & 0.572 & \\
\hline 1B. Pain-Avoiding & $12.47(8.43)$ & -5.21 & 0.000 & -0.49 (mod.) & $18.54(10.52)$ & -0.15 & 0.883 & \\
\hline 2A. Actively Modifying & $26.52(8.66)$ & -0.71 & 0.482 & & $24.91(8.41)$ & -1.19 & 0.236 & \\
\hline 2B. Passively Accommodating & $20.75(8.98)$ & -1.60 & 0.115 & & $23.84(8.88)$ & 1.17 & 0.243 & \\
\hline 3A. Self-Indulging & $17.54(7.30)$ & -4.28 & 0.000 & -0.46 (mod.) & $14.51(5.90)$ & $-4.28^{* * *}$ & 0.000 & -0.34 (mod.) \\
\hline 3B. Other Nurturing & $29.20(8.15)$ & 1.45 & 0.152 & & $34.15(6.54)$ & $3.93^{* * *}$ & 0.000 & 0.35 (mod.) \\
\hline \multicolumn{9}{|l|}{ Thinking Styles } \\
\hline 4A. Externally Focused & $24.76(8.58)$ & 1.77 & 0.080 & & 23.64 (8.19) & -1.36 & 0.178 & \\
\hline 4B. Internally Focused & $10.42(6.97)$ & -3.66 & 0.000 & -0.39 (mod.) & 11.61 (6.99) & 0.26 & 0.796 & \\
\hline 5A. Realistic/Sensing & $21.45(5.67)$ & 2.76 & 0.007 & 0.29 (low) & 20.98 (5.09) & $2.46^{*}$ & 0.016 & 0.22 (low) \\
\hline 5B. Imaginative/Intuiting & $15.33(6.65)$ & -5.12 & 0.000 & -0.45 (mod.) & $17.15(6.90)$ & $-2.19^{*}$ & 0.031 & -0.19 (low) \\
\hline 6A. Thought-Guided & $22.25(8.13)$ & -0.88 & 0.380 & & $14.67(8.06)$ & $-3.76^{* * *}$ & 0.000 & -0.38 (mod.) \\
\hline 6B. Feeling-Guided & $24.02(7.97)$ & -2.05 & 0.043 & -0.21 (low) & 30.59 (7.99) & 1.78 & 0.078 & \\
\hline 7A. Conservation-Seeking & 36.42 (10.69) & 0.85 & 0.400 & & 34.98 (9.92) & -1.42 & 0.158 & \\
\hline 7B. Innovation-Seeking & $20.80(7.72)$ & -3.89 & 0.000 & -0.37 (mod.) & $20.65(8.25)$ & $-2.36^{*}$ & 0.021 & -0.22 (low) \\
\hline \multicolumn{9}{|l|}{ Behaving Styles } \\
\hline 8A. Asocial/withdrawing & $19.84(8.70)$ & 1.93 & 0.057 & -0.20 (low) & $19.82(8.11)$ & 0.31 & 0.761 & \\
\hline 8B. Gregarious/outgoing & 31.19 (12.19) & 0.33 & 0.742 & & $26.05(9.68)$ & $-3.37^{* * *}$ & 0.001 & -0.32 (mod.) \\
\hline 9A. Anxious/hesitating & $14.31(8.83)$ & -4.39 & 0.000 & -0.42 (mod.) & $19.81(10.44)$ & 0.97 & 0.335 & \\
\hline 9B. Confident/asserting & $34.81(11.36)$ & 1.42 & 0.160 & & $26.34(8.96)$ & $-4.01^{* * *}$ & 0.000 & -0.35 (mod.) \\
\hline 10A. Unconventional/dissenting & $17.67(8.28)$ & -5.33 & 0.000 & -0.57 (high) & $17.18(6.97)$ & $-3.34^{* * *}$ & 0.001 & -0.27 (low) \\
\hline 10B. Dutiful/conforming & $40.99(9.08)$ & 1.05 & 0.296 & & 40.09 (8.58) & 0.95 & 0.343 & \\
\hline 11A. Submissive/yielding & $13.76(6.51)$ & -3.92 & 0.000 & -3.36 (mod.) & $17.03(8.00)$ & 0.17 & 0.863 & \\
\hline 11B. Dominant/controlling & $24.06(8.19)$ & -0.70 & 0.486 & & $19.06(-2.39)$ & $-3.68^{* * *}$ & 0.000 & -0.32 (mod.) \\
\hline 12A. Dissatisfed/complaining & $18.35(8.75)$ & -6.00 & 0.000 & -0.63 (high) & $8.70(9.59)$ & $-3.92^{* * *}$ & 0.000 & -0.39 (mod.) \\
\hline 12B. Cooperative/agreeing & $36.11(9.05)$ & 2.78 & 0.007 & 0.33 (mod.) & 41.45 (8.18) & $4.00^{* * *}$ & 0.000 & 0.36 (mod.) \\
\hline Iaj.t. Clinical Index & $51.50(12.30)$ & 0.85 & 0.339 & & 43.45 (13.45) & $-4.56^{* * *}$ & 0.000 & -0.59 (high) \\
\hline
\end{tabular}

${ }^{*} p<0.05 ;{ }^{* *} p<0.01 ;{ }^{* * *} p<0.001$. 
There were statistically significant differences between the fathers and the men from the normative population on 14 scales. According to the MIPS guidelines, statistically significant differences in a given bipolarity enhance the meaning of the scales regarding personality traits. Thus, the statistically significant differences in 3 bipolarities (Pleasure/Enhancing and Pain/Avoiding, Realistic/Sensing and Imaginative/Intuiting, Dissatisfied/complaining and Cooperative/agreeing), indicate that the personality style of the fathers in our sample is more motivated towards finding pleasure and enhancing in their lives (pleasure/enhancing), more oriented towards concrete and observable information (sensation), as well as more agreeableness in interpersonal relationships.

There were statistically significant differences between the mothers and the women from the normative population on 12 scales. Statistically significant differences in 3 bipolarities (Self-Indulging and Other Nurturing, Realistic/Sensing and Imaginative/Intuiting, Dissatisfied/complaining and Cooperative/agreeing) suggest that the mothers of the sample favor a style which is strongly protective, oriented to sensation (concrete and observable information) and more agreeable and acquiescent. Finally, the Clinical Index indicated a significantly lower level of psychological adjustment in the mothers' sample than in the normative group, the size of the effect was high ((Hypotheses 2)

Before performing the MANOVA (Hypothesis 3), the inclusion in the model of the covariates parental age (age of parents and child) and disability level was analyzed. We found no relationship between these covariates and the dependent variables.

The multivariate analysis Pillai's Trace show a statistically significant effect for gender [Pillai's $(25,150)=$ 0.55; $p<0.000$ ] and educational level (Pillai's $(50,302)=0.38 ; p<0.035$ ); but not for socioeconomic level (Pillai's $(25,150)=0.18, p<0.171)$, so we can say that the differences are explained by the gender of the subjects and their level of education. Therefore, we can state that multivariate differences are explained by the gender of the subjects and their level of education.

The univariate tests (see Table 2) showed a statistically significant effect of the variable gender in 19 of the 24 scales and in the Clinical Index, with moderate and high sizes of the effect. The fathers group differ significantly of the mothers group in: Self-Indulging, Externally Focused, Realistic/Sensing, Conservation-Seeking, Gregarious/outgoing scales $(p<0.05)$; Actively Modifying and Cooperative/agreeing scales $(p<0.01)$; and finally, highly significant differences in Passively Accommodating, Other Nurturing, Internally Focused, Imaginative/Intuiting, Thought-Guided, Feeling-Guided, Anxious/hesitating, Confident/asserting, Submissive/yielding and Dominant/controlling scales, and the Clinical Index $(p<0.001)$. Educational level was significant on three scales: the Primary Education group obtained significantly higher scores than the Secondary Education group in Other Nurturing scale $(p<0.01)$; significantly higher scores than the Secondary and Higher Education groups in Conservation-Seeking scale $(p<0.01)$; and also significantly higher scores than the Higher Education group in Dutiful/conforming scale $(p<0.05)$.

Economic level also was significant in 10 of the 24 scales and in the Clinical Index, with small and moderate sizes of the effect. The medium-low group obtained significantly higher scores than the medium-high group in: Passively Accommodating, Asocial/withdrawing, Anxious/hesitating and Submissive/yielding scales $(p<0.05)$. On the contrary, this group obtained significantly lower scores than the medium-high group in: Actively Modifying scale $(p<0.01)$, Externally Focused and Conservation-Seeking scales $(p<0.05)$, Gregarious/outgoing and Confident/asserting scales $(p<0.01)$ and in the Clinical Index $(p<0.01)$.

\section{Discussion}

As stated in the first hypothesis, personality styles are a proven source of information on the psychological organization/pattern and adaptive behavior of parents with a disabled child. We have identified personality profiles which are significantly different from those in the normative population.

Taking these differences into account, we can provide a characteristic profile of personality for fathers and mothers in the three dimensions mentioned above: motivating styles, thinking styles, and behaving styles.

In the group of men, the differences suggest a motivating style characterized by vitality, energy, optimism, and the search for positive reinforcement in the light of misfortune (pleasure-enhancing); less tendency towards preservation, pessimism and avoidance, than the normative population; and less individuality than men from the normative population. This motivating style suggests the presence of a strong protective factor, given that the decreased use of coping strategies based on escape-avoidance has been associated with greater psychological adjustment [23]-[25] [42]-[44]. 
Table 2. MANCOVA results from the MIPS scales and Clinical Index: Effects of the variables gender, educational level and socioeconomic level.

\begin{tabular}{|c|c|c|c|c|c|c|c|c|c|}
\hline \multirow{3}{*}{ MIPS scales } & \multicolumn{3}{|c|}{ GENDER } & \multicolumn{3}{|c|}{ EDUCATIONAL LEVEL } & \multicolumn{3}{|c|}{ SOCIOECONOMIC LEVEL } \\
\hline & \multicolumn{3}{|c|}{$\begin{array}{l}\text { Father }^{\mathrm{a}}(\mathrm{n}=83) \\
\text { Mother }^{\mathrm{b}}(\mathrm{n}=96)\end{array}$} & \multicolumn{3}{|c|}{$\begin{array}{l}\text { Primary education }^{1}(n=63) \\
\text { Secondary education }^{2}(n=62) \\
\text { Higher education }^{3}(n=54)\end{array}$} & \multicolumn{3}{|c|}{$\begin{array}{l}\text { Medium-Low }{ }^{\mathrm{a}}(\mathrm{n}=102) \\
\text { Medium-High }^{\mathrm{b}}(\mathrm{n}=77)\end{array}$} \\
\hline & $F(1,174)$ & $\eta^{2}$ & Contrast & $F(2,164)$ & $\eta^{2}$ & Contrast & $\mathrm{F}(1,164)$ & $\eta^{2}$ & Contrast \\
\hline \multicolumn{10}{|l|}{ Motivating Styles } \\
\hline 1A. Pleasure-Enhancing & $12.15^{* * *}$ & 0.065 & $a>b$ & 0.14 & 0.002 & & $7.75^{* *}$ & 0.043 & $\mathrm{a}<\mathrm{b}$ \\
\hline 1B. Pain-Avoiding & $24.82^{* * *}$ & 0.125 & $\mathrm{a}<\mathrm{b}$ & 1.01 & 0.011 & & 3.50 & 0.020 & \\
\hline 2A. Actively Modifying & $6.10^{* *}$ & 0.034 & $a>b$ & 1.50 & 0.017 & & $6.95^{* *}$ & 0.038 & $\mathrm{a}<\mathrm{b}$ \\
\hline 2B. Passively Accommodating & $19.99^{* * *}$ & 0.103 & $\mathrm{a}<\mathrm{b}$ & 0.32 & 0.004 & & $5.71^{*}$ & 0.032 & $a>b$ \\
\hline 3A. Self-Indulging & $5.34^{*}$ & 0.030 & $a>b$ & 0.54 & 0.006 & & 0.09 & 0.000 & \\
\hline 3B. Other Nurturing & $22.09^{* * *}$ & 0.113 & $\mathrm{a}<\mathrm{b}$ & $5.31^{* *}$ & 0.057 & $1>2$ & 1.36 & 0.008 & \\
\hline \multicolumn{10}{|l|}{ Thinking Styles } \\
\hline 4A. Externally Focused & $4.10^{*}$ & 0.023 & $a>b$ & 0.62 & 0.007 & & $5.67^{*}$ & 0.032 & $\mathrm{a}<\mathrm{b}$ \\
\hline 4B. Internally Focused & $14.53^{* * *}$ & 0.077 & $\mathrm{a}<\mathrm{b}$ & 1.52 & 0.017 & & 0.76 & 0.004 & \\
\hline 5A. Realistic/Sensing & $4.90^{*}$ & 0.027 & $a>b$ & 1.40 & 0.016 & & 1.68 & 0.004 & \\
\hline 5B. Imaginative/Intuiting & $13.98^{* * *}$ & 0.074 & $\mathrm{a}<\mathrm{b}$ & 0.08 & 0.001 & & 0.39 & 0.002 & \\
\hline 6A. Thought-Guided & $43.05^{* * *}$ & 0.198 & $a>b$ & 1.70 & 0.019 & & 1.07 & 0.006 & \\
\hline 6B. Feeling-Guided & $53.82^{* * *}$ & 0.236 & $\mathrm{a}<\mathrm{b}$ & 1.51 & 0.017 & & 0.01 & 0.000 & \\
\hline 7A. Conservation-Seeking & $5.10^{*}$ & 0.028 & $a>b$ & $5.87^{* *}$ & 0.063 & $1>3,2>3$ & $5.43^{*}$ & 0.030 & $\mathrm{a}<\mathrm{b}$ \\
\hline 7B. Innovation-Seeking & 0.32 & 0.002 & & 0.31 & 0.004 & & 0.14 & 0.001 & \\
\hline \multicolumn{10}{|l|}{ Behaving Styles } \\
\hline 8A. Asocial/withdrawing & 3.33 & 0.019 & & 0.10 & 0.001 & & $4.93^{*}$ & 0.028 & $\mathrm{a}>\mathrm{b}$ \\
\hline 8B. Gregarious/outgoing & $4.46^{*}$ & 0.025 & $a>b$ & 0.22 & 0.003 & & $13.907^{* * *}$ & 0.074 & $\mathrm{a}<\mathrm{b}$ \\
\hline 9A. Anxious/ hesitating & $25.79^{* * *}$ & 0.129 & $\mathrm{a}<\mathrm{b}$ & 1.25 & 0.014 & & $4.44^{*}$ & 0.025 & $a>b$ \\
\hline 9B. Confident/asserting & $44.41^{* * *}$ & 0.203 & $a>b$ & 0.36 & 0.004 & & $7.82^{* *}$ & 0.043 & $\mathrm{a}<\mathrm{b}$ \\
\hline 10A. Unconventional/dissenting & 2.07 & 0.012 & & 2.28 & 0.025 & & 0.04 & 0.000 & \\
\hline 10B. Dutiful/conforming & 0.34 & 0.002 & & $3.74^{*}$ & 0.041 & $1>3$ & 2.02 & 0.011 & \\
\hline 11A. Submissive/yielding & $12.29^{* * *}$ & 0.066 & $\mathrm{a}<\mathrm{b}$ & 0.34 & 0.004 & & $4.37^{*}$ & 0.024 & $a>b$ \\
\hline 11B. Dominant/controlling & $23.84^{* * *}$ & 0.120 & $a>b$ & 0.26 & 0.003 & & 3.51 & 0.020 & \\
\hline 12A. Dissatisfed/complaining & 3.54 & 0.020 & & 1.96 & 0.022 & & 1.79 & 0.010 & \\
\hline 12B. Cooperative/agreeing & $8.32^{* *}$ & 0.046 & $\mathrm{a}<\mathrm{b}$ & 0.78 & 0.009 & & 0.38 & 0.002 & \\
\hline Iaj.t. Clinical Index & $17.72^{* * *}$ & 0.092 & $a>b$ & 0.06 & 0.001 & & $7.61^{* *}$ & 0.042 & $\mathrm{a}<\mathrm{b}$ \\
\hline
\end{tabular}

The presence of a markedly pleasure-enhancing and motivating style is also related to the impulse to improve their own and other people's lives, and to reinforce their survival ability. This style would explain the great capacity to adapt to stress reported in other studies [24] [31] [45]-[47]. It has also been reported that concerns over the precise cause of the problem can drive these fathers into a long pilgrimage from one specialist to another due to their need to relieve feelings of impotence or guilt, rather than to dissatisfaction with the answers received. In this sense, the chronic character of the child's disease becomes a need to repair something that is irreparable [48]. This could be interpreted as a basic compensatory mechanism in humans, i.e., the drive to improve life, and to seek gratifying and pleasant experiences in the face of the pain and the sense of impotence and frustration generated by having a child with a severe disability [36].

On the other hand, mothers of children with chronic disabilities have a motivating style characterized by a strong predisposition toward caring for others, at the expense of oneself. Their style of being oriented to caring 
for others at the expense of themselves is closely related to caring for the child that mainly falls to mothers, and is also related to demands involved in taking care of a disabled child [4] [49]-[51]. This supports the findings of other studies that report increased levels of overprotection and receptivity towards children with disabilities [50]-[52], and positive assessments of the burden of care, as a way to adapt to a difficult situation such as the one these parents are experiencing [29] [30] [45] [53].

Secondly, the differences found in the cognitive dimension suggest that both fathers and mothers have a greater cognitive orientation toward direct experience, observable phenomena, and practical, real and objective information; they also indicate an extremely low predisposition to handle abstract and ambiguous information, such an abstract reasoning with a symbolic character. This cognitive style is related to a pragmatic coping strategy that shows a clear preference for the specific aspects of the present and the need to plan day-by-day. This propensity has been identified by other studies as an important factor of psychological adjustment that helps parents to face the daily stressors associated with taking care of children, protecting themselves from pain, and improving self-esteem and efficiency [25] [31] [48]. Together with this pragmatic style, the mothers in our sample showed less tendency to the logical and objective analysis of reality; and the fathers, showed less predisposition to handle feelings. Originality and innovation are not among their strengths.

Regarding behaving styles, that encompass the way people relate with each other, the parents in our sample appear maintain good control in their interpersonal relationships, are not submissive, are not submissive, and show good adjustment to social norms (conventional behavior). Both, although more accentuated in mothers, show an interpersonal style in which cooperation, harmony and engagement has priority over any individual interest.

No significant effects of the age and severity of child's disability. Although some studies associate the severity of a chronic condition in children with the psychological health of their mothers [7] [15], the majority of the empirical studies do not support such a hypothesis [2] [5] [54]. Usually it is difficult to reach a consensus on this issue due to the variability of the criteria used as a indicators of severity in different studies [55].

Despite the wide age range of children in our study, child age was not a particularly influential variable on families of children with chronic disability. Results agree with those of Wiegner and Donders [2], but contradict the findings of Ulus and collaborators [55].

The second hypothesis was also confirmed. As predicted, the different levels of psychological adjustment found between fathers and mothers indicate lower psychological adjustment among mothers and therefore, the existence of cognitive, affective or interpersonal behaviors that are not positive for their health and well-being. Our results are consistent with many other studies that suggest that mothers are at increased risk due to being the main caregiver [4] [7] [13] [22] [46] [56] [57].

The third hypothesis suggested that the gender, educational level and socioeconomic level would modulate the differences found in personality.

Concerning the moderating role of gender, the results are consistent with studies previous [24] [58]. The differences between fathers and mothers show a division along opposite personality dimensions which suggest a marked asymmetry in gender roles. The traditional masculine and feminine roles seem to be more accentuated among fathers and mothers of children with a chronic disability. The more common profile for the father matches the traditional stereotype of the external provider: a greater pleasure-enhancing style, cognitively more reflexive, and sociable, assertive and dominating. The mother's profile is associated with the traditional stereotype of caring for the child and being a housewife: they are more conservative and oriented to caregiving, more receptive to emotional information, and more indecisive, submissive and acquiescent than their partners.

In this regard, it is commonly agreed that the level of stress and psychological maladjustment among mothers is higher, and this is mainly due to the differences in the caregiving and work roles within the relationship [2] [56]. The role of the mother as the primary caregiver has also been associated with greater uncertainty among these women in relation to their image as mothers and with an increased tendency to being more conventional [57] [58]. Complying to a gender stereotype may help to justify, rationalize, and understand painful events, and provide a model when external and internal demands overpower available resources, as occurs among these parents [25]. Future studies could confirm these hypotheses by evaluating the different responses of parents, not only according to being a man or a woman, but also to specific gender variables and prevailing social norms that might lead to inequality and disadvantage among these women.

On the other hand, educational and socioeconomic levels, independently of being a man or a woman, seem to moderate to some extent the differences found in personality variables and psychological adjustment. 
In this sense, taking into account that some styles may be more effective than others regarding satisfactory adaptation to the environment [26]-[28] [40], the least adaptive personality styles, such as Pain-Avoidance, Passively accommodating, anxious/hesitating, Unconventional/Dissenting and Dissatisfied/Complaining styles, appear to be related to a low-to-medium socioeconomic level. Similarly, a medium-to-high socioeconomic level is associated with a more pleasure-enhancing, active, and transforming personality style, higher levels of extraversion, decisiveness and control, and, therefore with greater capacity for adaptation. However, low-to-medium educational level of the parents appears associated with more protective styles, cognitively more systematic and more conformist at the interpersonal level.

Regarding these findings, the economic level of the family has been associated with coping and psychological discomfort among parents in previous studies [51] [59] however, the educational level of parents has not been regarded as an important moderator of personal resources in parents with disabled children.

\section{Conclusions}

The present study analyzes the psychological adaptation of parents with children with congenital disabilities based on a model that focuses on the identification of adaptive resources, rather than on dysfunctional aspects. The personality styles evaluated provide a measure of the stability of the processes involved in parents' psychological adaptation, independently of the developmental stage of the child or the disease, and account for a wide range of psychologically relevant behavior, which may be of use to future research and intervention.

The results show significant behavioral tendencies that identify certain areas of vulnerability where parents may be putting their psychological health at risk, and at the same time, indicate behavioral resources that may act as protective factors.

Being a man or a woman has a differential impact that appears to be related to the adopting traditional gender roles by parents, as a way of facing and adapting to the situation. This would place mothers in a situation of greater vulnerability, as they show less psychological adjustment and adaptive personality styles than fathers. Therefore, gender issues may be acting in concert to differentiate how such mothers and fathers adapt psychologically. The educational and socioeconomic levels of parents could also act as risk factors in their adaptive functioning. Researchers and clinicians should explore these sociodemographic factors as they may contribute to the psychological adjustment of parents.

The present study has some limitations. The sample is comprised exclusively by parents belonging to parents' associations of children with chronic physical illness. To further our understanding of psychological adaptation of parents of children with a congenital disability, it would be relevant to study a more diverse sample. Finally, it underlines the limit of the use of self-report questionnaires. Although this study goes beyond the use of self-report measures, and provides a psychometrically standardized measure, to further our understanding of parental adaptation to chronic stress, future studies should include information gathered via multiple methods and from multiple sources.

Although these profiles may not always account for the great diversity of parental responses, they may serve as indicators of the way parents face to child's disability. Gaining a deeper understanding of the motivational, cognitive and behavioral dimensions involved in the adaptive functioning of these parents, and identifying those variables that are relevant to their well-being and psychological adjustment-as well as the educational and socioeconomic level of the family - could be of great use to the professional teams who provide these families with help and counselling, and may help them to design better intervention strategies to optimize personal resources.

\section{Acknowledgements}

We thank all fathers and mothers of children with spina bifida, cerebral palsy, cleft lip and palate, and their respective associations, for their commitment and involvement in the project.

\section{References}

[1] Wallander, J.L. and Noojin, A.B. (1995) Mothers’ Report of Stressful Experiences Related to Having a Child with a Physical Disability. Children's Health Care, 24, 245-256. http://dx.doi.org/10.1207/s15326888chc2404 4

[2] Wiegner, S. and Donders, J. (2000) Predictors of Parental Distress after Congenital Disabilities. Journal Developmental Behavioral Pediatrics, 21, 271-274. http://dx.doi.org/10.1097/00004703-200008000-00003 
[3] Ki, Y.W. and Joanne, C.C.Y. (2014) Stress and Marital Satisfaction of Parents with Children with Disabilities in Hong Kong. Psychology, 5, 349-357. http://dx.doi.org/10.4236/psych.2014.55045

[4] Vermaes, I.P.R., Janssens, J.M.A.M., Bosman, A.M.T. and Gerris, J.R.M. (2005) Parents’ Psychological Adjustment in Families of Children with Spina Bifida: A Meta-Analysis. BMC Pediatrics, 32, 1-13.

[5] Tifferet, S., Manor, O., Elizur, Y., Friedman, O. and Constantini, S. (2010) Maternal Adaptation to Pediatric Illness: A Personal Vulnerability Model. Children's Health Care, 39, 91-107. http://dx.doi.org/10.1080/02739611003679840

[6] Macias, M.M., Clifford, S.C., Saylor, C.F. and Kreh, S.M. (2001) Predictors of Parenting Stress in Families of Children with Spina Bifida. Children's Health Care, 30, 57-65. http://dx.doi.org/10.1207/S15326888CHC3001_5

[7] Uguz, S., Toros, F., Inanc, B.Y. and Colakkadioglu, O. (2004) Assessment of Anxiety, Depression and Stress Levels of Mothers of Handicapped Children. Klinik Psikiyatri Dergisi, 7, 42-47. http://www.klinikpsikiyatri.org/files/journals/1/185.pdf

[8] Weigl, V., Rudolph, M., Eysholdt, U. and Rosanowski, F. (2005) Anxiety, Depression, and Quality of Life in Mothers of Children with Cleft Lip/Palate. Folia Phoniatricaet Logopaedica, 57, 20-27. http://dx.doi.org/10.1159/000081958

[9] Macias, M.M., Roberts, K.M., Saylor, C.F. and Fussell, J.J. (2006) Toileting Concerns, Parenting Stress, and Behavior Problems in Children with Special Health Care Needs. Clinical Pediatrics, 45, 415-422. http://dx.doi.org/10.1177/0009922806289616

[10] Glenn, S., Cunningham, C., Poole, H., Reeves, D. and Weindling, M. (2009) Maternal Parenting Stress and Its Correlates in Families with a Young Child with Cerebral Palsy. Child: Care, Health and Development, 35, 71-78. http://dx.doi.org/10.1111/j.1365-2214.2008.00891.x

[11] Drotar, D., Baskiewicz, A., Irvin, N.A., Kennell, J.H. and Klaus, M.H. (1975) The Adaptation of Parents to the Birth of an Infant with a Congenital Malformation: A Hypothetical Model. Pediatrics, 56, 710-717.

[12] Koomen, H.M.Y. and Hoeksma, J.B. (1992) Maternal Interactive Behaviour towards Children with and Children without Cleft Lip and Palate. Early Development and Parenting, 1, 169-181. http://dx.doi.org/10.1002/edp.2430010306

[13] Holmbeck, G.N, Gorey-Ferguson, L., Hudson, T., Seefeldt, T., Shapera, W., Turner, T. and Uhler, J. (1997) Maternal, Paternal, and Marital Functioning in Families of Preadolescents with Spina Bifida. Journal of Pediatric Psychology, 22, 167-181. http://dx.doi.org/10.1093/jpepsy/22.2.167

[14] Barlow, J.H. and Ellard, D.R. (2006) The Psychosocial Well-Being of Children with Chronic Disease, Their Parents and Siblings: An Overview of the Research Evidence Base. Child: Care, Health and Development, 32, 19-31. http://dx.doi.org/10.1111/j.1365-2214.2006.00591.x

[15] Berge, J.M., Patterson, J.M. and Rueter, M. (2006) Marital Satisfaction and Mental Health of Couples with Children with Chronic Health Conditions. Families Systems \& Health, 24, 267-285. http://dx.doi.org/10.1037/1091-7527.24.3.267

[16] Aldwin, C.M. and Brustrom, J. (1997) Theories of Coping with Chronic Stress: Illustrations from the Health Psychology and Aging Literatures. In: Gottlieb, B.H., Ed., Coping with Chronic Stress, Plenum Press, New York, 75-99. http://dx.doi.org/10.1007/978-1-4757-9862-3_3

[17] Lazarus, R.S. (2006) Stress and Emotion: A New Synthesis. Springer Publishing Company, New York.

[18] Cousino, M.K. and Hazen, R.A. (2013) Parenting Stress among Caregivers of Children with Chronic Illness: A Systematic Review. Journal of Pediatric Psychology, 38, 809-828. http://dx.doi.org/10.1093/jpepsy/jst049

[19] Cuzzocrea, F., Larcan, R. and Westh, F. (2014) Family and Parental Functioning in Parents of Disabled Children. Nordic Psychology, 65, 271-287. http://dx.doi.org/10.1080/19012276.2013.824201

[20] Boll, T.J., Dimino, E. and Mattsson, A.E. (1978) Parenting Attitudes: The Role of Personality Style and Childhood Long-Term Illness. Journal of Psychosomatic Research, 22, 209-213. http://dx.doi.org/10.1016/0022-3999(78)90026-0

[21] Dean, R.S. and Jacobson, B.P. (1982) MMPI Characteristics for Parents of Emotionally Disturbed and Learning-Disabled Children. Journal of Consulting and Clinical Psychology, 50, 775-777. http://dx.doi.org/10.1037/0022-006X.50.5.775

[22] Vermaes, I.P.R., Janssens, J.M.A.M., Mullaart, R.A., Vinck, A. and Gerris, J.R.M. (2008) Parents' Personality and Parenting Stress in Families of Children with Spina Bifida. Child: Care, Health and Development, 34, 665-674. http://dx.doi.org/10.1111/j.1365-2214.2008.00868.x

[23] Glidden, L.M., Billings, F.J. and Jobe, B.M. (2006) Personality, Coping Style and Well-Being of Parents Rearing Children with Developmental Disabilities. Journal of Intellectual Disability Research, 50, 949-962. http://dx.doi.org/10.1111/j.1365-2788.2006.00929.x

[24] Limiñana-Gras, R.M. (2006) Personalidad y Adaptación Psicológica Parental en Discapacidad [Personality and Parental Psychological Adjustment in Disability]. Doctoral Thesis, University of Murcia, Murcia.

http://www.tdx.cat/handle/10803/283282 
[25] Limiñana Gras, R., Corbalán, F.J. and Sánchez-López, M.P. (2009) Thinking Styles and Coping When Caring for a Child with Severe Spina Bifida. Journal of Developmental and Physical Disabilities, 19, 125-134. http://dx.doi.org/10.1007/s10882-009-9133-0

[26] Millon, T. (1990) Toward a New Personality: An Evolutionary Model. Wiley, New York.

[27] Millon, T. (1994) Millon Index of Personality Styles, Manual. The Psychological Corporation, San Antonio.

[28] Millon, T. (2004) Millon Index of Personality Styles, Manual Revised. Pearson Assessments, Minneapolis.

[29] Schwartz, C. (2003) Parent of Children with Chronic Disabilities: The Gratification of Caregiving. Families in Society, 84, 576-584. http://dx.doi.org/10.1606/1044-3894.143

[30] Kearney, P.M. and Griffin, T. (2001) Between Joy and Sorrow: Being a Parent of a Child with Developmental Disability. Journal of Advanced Nursing, 34, 582-592. http://dx.doi.org/10.1046/j.1365-2648.2001.01787.x

[31] Barakat, L.P. and Linney, J.A. (1995) Optimism, Appraisals and Coping in the Adjustment of Mothers and Their Children with Spina Bifida. Journal of Child and Family Studies, 4, 303-320. http://dx.doi.org/10.1007/BF02233965

[32] Limiñana Gras, R.M., CorbalánBerná, F.J. and Patró Hernández, R.M. (2007) Coping and Psychological Adaptation in Parents of Children with Cleft Palate. Anales de Psicología, 23, 201-206. http://www.um.es/analesps/v23/v23_2/04-23_2.pdf

[33] Cuéllar-Flores, I. and Sánchez-López, M.P. (2012) Adaptaciónpsicológicaen personas cuidadoras de familiaresensituación de dependencia [Psychological Adaptation in Caregivers of Relatives in a Situation of Dependence]. Clínica y Salud, 23, 141-152. http://dx.doi.org/10.5093/cl2012a9

[34] Sandler, A.D. (2010) Children with Spina Bifida: Key Clinical Issues. Pediatric Clinics of North America, 57, 879-892. http://dx.doi.org/10.1016/j.pcl.2010.07.009

[35] Rosenbaum, P., Paneth, N., Leviton, A., Goldstein, M., Bax, M., Damiano, D., Dan, B. and Jacobsson, B. (2007) A Report: The Definition and Classification of Cerebral Palsy April 2006. Developmental Medicine and Child Neurology. Supplement, 109, 8-14.

[36] Gorlin, R.J., Cohen, M.M. and Hennekam, R.C.M. (2001) Syndromes of the Head and Neck. Oxford University Press, New York.

[37] World Health Organization (1980) International Classification of Impairments, Disabilities and Handicaps. A Manual of Classification Relating to the Consequences of Disease. WHO, Geneva.

[38] World Health Organization (2001) International Classification of Functioning, Disability and Health (ICF). WHO, Geneva.

[39] Millon, T. (2001) Inventario de Estilos de Personalidad de Millon, Manual. [Millon Index of Personality Styles, Manual]. Adaptación de M.P. Sánchez-López, J.F. Díaz-Morales and M.E. Aparicio-García. TEA Ediciones, Madrid.

[40] Cardenal, V. and Fierro, A. (2001) Sexo y edadenestilos de personalidad, bienestar personal y adaptación social. Psicothema, 13, 118-126. http://www.psicothema.com/psicothema.asp?id=422

[41] Keppel, G. (1991) Design and Analysis: A Researcher’s Handbook. 3rd Edition, Prentice Hall, Englewood Clifts, New York.

[42] Judge, S.L. (1998) Parental Coping Strategies and Strengths in Families of Young Children with Disabilities. Family Relations, 47, 263-268. http://dx.doi.org/10.2307/584976

[43] Abbeduto, L., Seltzer, M., Shattuck, P., Krauss, M., Orsmond, G. and Murphy, M. (2004) Psychological Well-Being and Coping in Mothers of Youths with Autism, Down Syndrome, or Fragile X Syndrome. American Journal on Mental Retardation, 109, 237-254. http://dx.doi.org/10.1352/0895-8017(2004)109<237:PWACIM>2.0.CO;2

[44] Stoneman, Z. and Gavidia-Payne, S.T. (2006) Marital Adjustment in Families of Young Children with Disabilities: Associations with Daily Hassles and Problem-Focused Coping. American Journal on Mental Retardation, 111, 1-14. http://dx.doi.org/10.1352/0895-8017(2006)111[1:MAIFOY]2.0.CO;2

[45] Lemanek, K.L., Jones, M.L. and Lieberman, B. (2000) Mothers of Children with Spina Bifida: Adaptational and Stress Processing. Children's Health Care, 29, 19-35. http://dx.doi.org/10.1207/S15326888CHC2901_2

[46] Limiñana Gras, R., Corbalán Berná, F.J. and Calvo Llena, M.T. (2009) Resiliencia y discapacidad: unaaproximaciónpositiva al estudio de la adaptación parental enfamilias de niños con espinabífida [Resilience and Disability: A Positive Approach to Parental Adaptation in Families of Children with Spina Bifida]. Editorial Universidad de Murcia (EDITUM), Murcia.

[47] Hall, H.R., Neely-Barnes, S.L., Graff, J.C., Krcek, T.E., Roberts, R.J. and Hankins, J.S. (2012) Parental Stress in Families of Children with a Genetic Disorder/Disability and the Resiliency Model of Family Stress, Adjustment, and Adaptation. Issues in Comprehensive Pediatric Nursing, 35, 24-44. http://dx.doi.org/10.3109/01460862.2012.646479

[48] Irvin, N.A., Kennell, J.H. and Klaus, M.H. (1976) Caring for Parents of an Infant with a Congenital Malformation. In: Klaus, M.H. and Kennell, J.H., Eds., Maternal-Infant Bonding, CV Mosby, St. Louis, 167-208. 
[49] Dorner, S. (1973) Psychological and Social Problems of Families of Adolescent Spina Bifida Patients: A Preliminary Report. Developmental Medicine and Child Neurology, 15, 24-26. http://dx.doi.org/10.1111/j.1469-8749.1973.tb04937.x

[50] Erickson, M. and Upshur, C.C. (1989) Caretaking Burden and Social Support: Comparison of Mothers of Infants with and without Disabilities. American Journal on Mental Retardation, 94, 250-258.

[51] Wallander, J.L. and Venters, T.L. (1995) Perceived Role Restriction and Adjustment of Mothers of Children with Chronic Physical Disability. Journal of Pediatric Psychology, 20, 619-632. http://dx.doi.org/10.1093/jpepsy/20.5.619

[52] Holmbeck, G.N., Coakley, R.M., Hommeyer, J.S., Shapera, W.E. and Westhoven, V.C. (2002) Observed and Perceived Dyadic and Systemic Functioning in Families of Preadolescents with Spina Bifida. Journal of Pediatric Psychology, 27, 177-189. http://dx.doi.org/10.1093/jpepsy/27.2.177

[53] Noojin, A.B. and Wallander, J.L. (1997) Perceived Problem-Solving Ability, Stress, and Coping in Mothers of Children with Physical Disabilities: Potential Cognitive Influences on Adjustment. International Journal of Behavioral Medicine, 4, 415-432. http://dx.doi.org/10.1207/s15327558ijbm0404 10

[54] Manuel, J., Naughton, M.J., Balkrishnan, R., Paterson Smith, B. and Koman, L.A. (2003) Stress and Adaptation in Mothers of Children with Cerebral Palsy. Journal of Pediatric Psychology, 28, 197-201. http://dx.doi.org/10.1093/jpepsy/jsg007

[55] Ulus, Y., Tander, B., Akyol, Y., Ulus, A., Tander, B., Bilgici, A., Kuru, O. and Akbas, S. (2012) Functional Disability of Children with Spina Bifida: Its Impact on Parents’ Psychological Status and Family Functioning. Developmental Neurorehabilitation, 15, 322-328. http://dx.doi.org/10.3109/17518423.2012.691119

[56] Kazak, A.E. and Marvin, R.S. (1984) Differences, Difficulties and Adaptation: Stress and Social Network in Families with a Handicapped Child. Family Relations, 33, 67-77. http://dx.doi.org/10.2307/584591

[57] Vermaes, I.P.R., Gerris, J.R.M. and Janssens, J.M.A.M. (2007) Parents' Social Adjustment in Families of Children with Spina Bifida: A Theory-Driven Review. Journal of Pediatric Psychology, 32, 1214-1226. http://dx.doi.org/10.1093/jpepsy/jsm054

[58] Limiñana Gras, R.M. and Patró Hernández, R.M. (2004) Mujer y Salud: Trauma y cronificaciónenmadres de discapacitados [Women and Health: Trauma and Chronification in Mothers of Disabled Children]. Anales de Psicología, 20, 47-54.

[59] Cleve, L.V. (1989) Parental Coping in Response to Their Child's Spina Bifida. Journal of Pediatric Nursing, 4, 172176. 


\section{SOCIODEMOGRAPHIC AND HEALTH HISTORY QUESTIONNAIRE}

CODE:

Completedby:

DATA:

PERSONAL DATA OF THE CHILD:

NAMES AND SURNAMES:

NATIONALITY:

DATE AND PLACE OF BIRTH:

ADDRESS:

MEDICAL DIAGNOSIS:

DATE OF FIRST DIAGNOSIS:

PERCENTAGE OF DISABILITY AND DATE OF ISSUE:

ASSOCIATION TO WHICH BELONGS:

NUMBER OF SURGERIES: NUMBER OF HOSPITALIZATIONS:

PHYSICAL AND NEUROLOGICAL COMPLICATIONS, MALFORMATIONS, OR DISEASESASSOCIATED:

OTHER ALTERATIONS ASSOCIATED:

PERSONAL DATA OF THE FATHER:

NATIONALITY:

DATE OF BIRTH AND AGE:

PROFESSION:

\section{MARITAL STATUS:}

Single 1

Separated/divorced 3

LEVEL OF STUDIES COMPLETED:

Withoutstudies 1

Secondaryeducation 3

CURRENT EMPLOYMENT SITUATION

Employed 1

Employed 3

Retiredorpensioner 5

Married
Widowed

Primaryeducation 2

Highereducation 4

Household chores ___ 2

Unemployed 4

Others 6 
SOCIOECONOMIC LEVEL:

Level upper-middle 1

Level lower-middle 2

PERSONAL DATA OF THE MATHER:

NATIONALITY:

DATE OF BIRTH AND AGE:

PROFESSION:

MARITAL STATUS:

Single 1

Separated/divorced 3

Married 2

LEVEL OF STUDIES COMPLETED:

Withoutstudies 1

Secondaryeducation 3

Widowed 4

CURRENT EMPLOYMENT SITUATION

Employed 1

Employed 3

Retiredorpensioner 5

SOCIOECONOMIC LEVEL:

Level upper-middle 1

$\begin{array}{ll}\text { Primaryeducation } & 2 \\ \text { Highereducation } & \end{array}$

Household chores 2

Unemployed 4

Others 6

Level lower-middle 2 